\title{
A Reappraisal of the Environmental Problems of Atmospheric Pollution, Air Quality Emissions and Applicable Control Mechanisms in the Detection and Evaluation in the Niger Delta Region of Nigeria, Global Trends and Emerging Developments in the Light of the Recently Released Flare Gas (Prevention of Waste and Pollution) Regulations, 2018, in Nigeria
}

\author{
Dr. Sylvanus, Abila \\ Senior Lecturer and Head of Department, Private and Property Law, Faculty of Law Niger Delta University, \\ Wilberforce Island, Bayelsa State, Nigeria \\ Obasohan, O.J. L.LM, BL, MPA, \\ Lecturer, Benson Idahosa University, Benin City, Edo State, Nigeria
}

\begin{abstract}
The paper carries out a review of the environmental problems associated with atmospheric pollution, air quality emissions and applicable control mechanisms in the detection and evaluation in the Niger Delta region of Nigeria in the light of global trends and best practices given the magnitude of gas flaring taking place in Nigeria's Niger Delta daily. This is flowing from the findings that gas flaring continues to be a major health hazard to humanity, domestic and global environment. Also considered are the Challenges facing air quality and carbon management in Nigeria and the place of the ongoing National Space Research and Development Agency (NASRDA) funded research on air quality and carbon management and the recent release of the twin regulations of: the Flare Gas (Prevention Of Waste And Pollution) Regulations, 2018 and the Nigerian Gas Flare Commercialization Programme (NGFCP) by the Federal Government Of Nigeria aimed at stopping gas flares in the year, 2020. The paper adopts an admixture of the historical, comparative, the law and development and empirical approaches in appropriate cases.

Keywords: Reappraisal, Environmental Problems, Atmospheric Pollution, Nuisance, Air Quality Emissions, Applicable Control Mechanisms, Detection, Evaluation, Niger Delta Region of Nigeria, Global Trends, Emerging Developments, The Flare Gas (Prevention of Waste and Pollution) Regulations, 2018.
\end{abstract}

DOI: $10.7176 /$ JLPG/92-17

Publication date: December $31^{\text {st }} 2019$

\subsection{BACKGROUND:}

According to the United Nations Environmental Programme of Ogoni land, "Nigeria is one of Africa's largest countries and it's most populous [and] situated in West Africa. The country covers an area of 923,768 km2, with an estimated 4,049 $\mathrm{km}$ of land boundaries, shared with Cameroon in the east, the Republic of Niger in the north, Chad in the north-east and Benin in the west. In the south, Nigeria's 853-km long coastline opens onto the Atlantic Ocean. The southern lowlands merge into the central hills and plateaus, with mountains in the south-east and plains in the north. The country's largest river is the Niger, which joins with the Benue River to form a confluence at Lokoja. The Niger Delta, located in the southernmost part of Nigeria and covering an area of some $70,000 \mathrm{~km} 2$, is the largest river delta in Africa and the third largest in the world.... From a coastal belt of swamps, stretching northwards the land becomes a continuous rainforest which gradually merges with woodland and savanna grasslands in central Nigeria. The swamp, forest and woodland areas occupy about 12 per cent of the delta's land surface."1

\subsection{INTRODUCTION:}

It is no longer news that gas flaring and other sources if air pollution constitute a veritable hazards on human beings, plants and wildlife as same cause acid rain which acidifies the lakes, streams, damages, crops and vegetation. Atmospheric pollution have also being discovered to reduce farm yields, harms human health, lives and livelihood; increases the risk of respiratory illnesses, asthma and cancer and often causes chronic bronchitis,

\footnotetext{
${ }^{1}$ See the United Nations Environment Programme. (C) 2011, United Nations Environment Programme. ISBN: 978-92-807-3130-9, Job No.: DEP/1337/GE. United Nations Environment Programme, P. 20. See also United Nations Development Programme (UNDP), Niger delta human development report. UNDP, Abuja, Nigeria 2006. Moffat, D. \& Linden, O., Perception and realities: assessing priorities for sustainable development in the Niger River delta. Ambio, 24, pp. 527-538. 995. ERML, Environmental and socio-economics characteristics of the Niger Delta. Niger Delta Environmental Survey Report. 1997. Abam, T.S.K., Regional hydrological research perspectives in the Niger Delta. Hydrological Sciences, 46, pp. 13-25. 2001.
} 
decrease lung function, blindness, impotency, miscarriages and premature deaths. Gas flares have also being established to impoverished entire human populations. ${ }^{1}$

A proper starting point in attempting to define the term 'pollution' is to consider a definition offered by the European Union 1996 Council Directive on Integrated Pollution Prevention and Control (IPPC) which defined concept as:

"The direct or indirect introduction as a result of human activity, of substances, vibrations, heat or noise into the air, water or land which may be harmful to human health or the quality of the environment, result in damage to material property, or impair or interfere with amenities and other legitimate uses of the environment". ${ }^{2}$

There is no gainsaying the fact that both organic, inorganic and other air pollutants have been established to bring about injurious healthiness and ecological impacts ranging from untimely demises, breathing disorders. Recent scientific findings clearly show that deaths caused by air pollution around the globe has risen to an estimate of about 2 million persons yearly. ${ }^{3}$ Several other negative impacts of air pollution include loss of plant and animal life, soil and water toxicities.

It is worrisome that, in modern day Nigeria studies on air quality valuation studies appear concentrated almost exclusively in cities in Nigeria (probably because of the fact that it is the cities that manufacturing processes, domestic undertakings, road traffic overcrowding etc, form major causes of air pollution ${ }^{4}$ ) and not in the rural areas where majority of the citizens of Nigeria are concentrated. Additionally, majority of the said studies have been undertaken independently and so bereft of any systematic measurements of air quality by the Federal Government of Nigeria or any of its agencies. ${ }^{5}$ It has been demonstrated through several evaluations conducted on manufacturing estates, selected landfill-sites and heavy stream of traffic locations in and around Lagos, for example, showed that typical "concentrations of carbonmonoxide (CO) in heavy traffic stations was 49.32ppm, while at industrial estates showed 36.75ppm and at dumpsites, 10.76ppm. Sulphur dioxide (SO2) averages were $0.166 \mathrm{ppm}$ at the traffic stations, while $0.670 \mathrm{ppm}$ levels were detected at both industrial and dumpsites. The NOX concentrations were $0.220 \mathrm{ppm}$ at the dumpsites and $0.333 \mathrm{ppm}$ at both industrial and traffic stations". ${ }^{6}$ It must be appreciated that the World Health Organization (WHO) ideals for CO, SO2 and NOx are $5 \mathrm{ppm}$ for 8 -hour regular, $0.45 \mathrm{ppm}$ for 24 -hour regular and $0.25 \mathrm{ppm}$ for 24 -hour regular correspondingly. ${ }^{7}$ The above results give the clear impression that air quality difficulties arising from waste dumping in Nigeria, manufacturing and domestic operations and conveyance is prevalent. The same is true of the prevalence of gas flaring in Nigeria $^{8}$ it is a well-known fact, for example, that air pollution in relationship with oil and gas extraction occurs, in different ways, which include: blowouts, geothermal steam and gas flaring. Different types of air pollution in relation to oil and gas extractions namely; blowout, geothermal steam along with other impacts of gas flaring and its impacts on the atmosphere in the Niger Delta region in Nigeria, Africa and the world as a whole are known and well documented. ${ }^{9}$

Blowouts refer to sudden and violent "escapes of gasses into the atmosphere". Such escapes occur when the pressure built around oil/gas wells become heavier than the wells' hydrostatic weights. ${ }^{10}$ The composition and character of the atmosphere is thereby altered to the detriment of the entire ecosystem including man. Yet, blowout is a very common feature associated drilling daily in the Niger Delta region of Nigeria. ${ }^{11}$ On the other hand geothermal steam refers to "the steam which is emitted into the atmosphere in the normal process of

${ }^{1}$ Kiikpoye K.A. Op cit 272) See also Abila S.E: Impacts of Oil/Gas operations on the environment and summary of the legal regime governing the exploration and exploitation of oil mineral resources in Nigeria's Niger Delta (2018) the university of port Harcourt journal of private law, Vol. 3, Pp. 162-166.

${ }^{2}$ IPPC, Council Directive 96/61/EC of 24 September 1996 concerning integrated pollution prevention and control. Official Journal L 257, 10/10/1996 P. 0026 - 0040. 1996. Online: http://eurlex.europa.eu/LexUriServ/LexUriServ.do?uri=CELEX:31996L0061:EN:HTML.

${ }^{3}$ World Health Organisation, WHO, Reducing risks, promoting healthy life. The World Health Report 2002. Geneva. 2002. Online. http://www.who.int/whr/2002/en/whr02_en.pdf.

${ }^{4}$ Taiwo, O., The case of Lagos - air quality improvement project. Presentation for the Lagos Metropolitan Area Transport Authority. 2005 Online. www.cleanairnet.org/ssa/1414/articles-69320 Taiwo.pdf. See also Ajao, E.A. \& Anurigwo, S., Land-based sources of pollution in the Niger Delta, Nigeria. Ambio, 31, pp. 442-445. 2002. See also Baumbach, G., Vogt, U., Hein, K.R.G., Oluwole, A.F., Ogunsola, O.J., Olaniyi, H.B., and Akeredolu, F.A., Air pollution in a large tropical city with high traffic density - results of measurements in Lagos, Nigeria. The Science of the Total Environment, 169, pp. 25-31. 1995.

${ }^{5}$ Taiwo, O., The case of Lagos - air quality improvement project. Presentation for the Lagos Metropolitan Area Transport Authority. 2005 Online. www.cleanairnet.org/ssa/1414/articles-69320 Taiwo.pdf.

${ }^{6}$ Ibid.

${ }^{7}$ World Bank, Air Quality Standards. 1995 line.http://www.worldbank.org/html/fpd/em/power/standards/airqstd.stm\#who

${ }^{8}$ Isuwa, S., Nigeria: transportation, major cause of air pollution. Report of the Director General of National Environmental Standards and Regulations Enforcement Agency (NESREA) at a seminar on WHO Air Quality Guidelines. 2008. Online: www.allafrica.com/stories/200804040160.html.

${ }^{9}$ See below footnote 15 and 16 .

${ }^{10}$ The sources discussed in this section are derived from D. Elsom, Atmospheric Pollution: A Global Problem, (2d ed. 1992) 369-70; M. Squillace, Environmental Law: Air Pollution (2d ed. 1992) 1-12; Urban Air Pollution in Megacities of the World, (WHO/UNEP Publication, Blackwell Publishers, London 1992), A. Wild, Soils and the Environment, (Cambridge, 1996) p. $211-232$.

${ }^{11}$ Chemical Pollution, Earth and UNEP 1992 at p. 19. 
drilling. The steam so emitted consists of hydrogen sulphide, methane and ammonia. And on reaching the earth surface, the hydrogen sulphide is converted into sulphur dioxide with its attendant harmful effects on plants and animals including man. Amonia is known to combine with other compounds in the atmosphere in bringing about acidic rain. ${ }^{1}$ However, "Shell Petroleum Development Corporation (SPDC) in its 2006 Annual report stated that the oil industry submitted a proposal to the oil industry regulatory body, the Department of Petroleum Resources (DPR) for air quality assessment in the Niger Delta only in 2006. This effort to assess air quality in the Niger Delta came after five decades of oil exploration, and gas flaring, in the region. " 2

Most of the ongoing gas flaring and atmospheric pollution in Nigeria take place in the Niger Delta region of Nigeria. It is without doubts that the Niger Delta is located in the southern part of Nigeria. It is also a wellknown fact that the region suffers from human and environmental issues of both national and international concern, in terms of the environmental pollution; impoverishment of the local people despite the wealth being generated from the region; security of human lives; property and infrastructure due to militancy; community agitations and youth unrest. ${ }^{3}$ This paper, however, gives a brief description of the Niger Delta environment and also highlights the major anthropogenic activities resulting in air pollution in the Niger Delta which include transportation, burning of fossil fuels for industrial and domestic use and waste disposal.

\subsection{ENVIRONMENTAL PROBLEMS OF THE NIGER DELTA REGION OF NIGERIA ARISING FROM OIL/GAS OPERATIONS:}

There exists a large literature from various intellectual divides on the negative impacts of oil pollution in the oil producing communities in the Niger Delta region in several ways. "Environmental problems of the Niger Delta region of Nigeria arising from oil/gas operations have been graded to include: (a) Socio-Economic Impacts which signposted by the destruction of traditional means of livelihood, the destruction of the ecosystem and biodiversity, the depletion of fish population. (b) physico-health impacts which include the health risks, the destruction of zinc roof, water pollution, (c) socio-culture Impacts etc. (d) a replication of erosion, flood and climate change adversely which affect the environment and threatened an imminent collapse of the ecosystem. Oil spillage that occurred daily in the Niger Delta region with the attendant problems causing the people to face severe suffering from the advent of oil exploration in the area till date are numerous. ${ }^{5}$ Suffice it to reiterate that some of the negative effect of activities of multinational oil companies include air pollution, soil pollution, soil degradation, health risk among others. ${ }^{6}$ Furthermore, the destruction of zinc roof, one of the increasing socioeconomic costs to most oil producing communities resulting from oil pollution is the rapidity with which zinc roofs are easily corroded. Houses with zinc roofs that are close to the locations of the flare stacks do not last for two years before they become corroded. This is different from other areas where zinc roofs last for at least ten years. This is a common trend that is also observed in other parts of the Niger Delta where oil extraction is presently taking place. Zinc corrosion has added another dimension to the increasing socio-economic costs. It is a common knowledge that acid rain oxidizes zinc through the process of oxidation to form zinc oxides. This oxidation process is traced to be responsible for the corrosion. This has led homeowners to resort to purchase of the expensive asbestos with its obvious potential health hazards."7

\section{O.4 AIR QUALITY, EMISSIONS AND APPLICABLE CONTROL MECHANISMS IN THEIR DETECTION AND EVALUATION}

Although emissions of $\mathrm{CO} 2$ and other greenhouse gases (GHGs) are recognized as contributing to climate change problem in Nigeria. ${ }^{8}$ However, an existing report indicates that the issue of air quality is not recognized

${ }^{1}$ Ibid.

${ }^{2}$ Shell Petroleum Development Corporation, SPDC, People and the environment. Shell Nigeria Annual Report 2006. Shell Visual Media Services, London. 2006.

${ }^{3}$ See below footnote 15 and 16 .

${ }^{4}$ See generally, Chijioke, Basil Onuoha, Ebong, Itoro Bassey \& Henry Ufomba "The Impact of Oil Exploration and Environmental Degradation in the Niger Delta Region of Nigeria: A Study of Oil Producing Communities in Akwa Ibom State" the Global Journal of human-social science: (F) political science, International Research Journal. Online ISSN: 2249-460x \& Print ISSN: 0975-587X, Volume 18 Issue 3 Version 1.0 Year 2018, Pp. 8 - 13.

${ }^{5}$ Ibid. See also Abila, Sylvanus, Ph.D: "Re-evaluating the stages of oil mineral resources extraction and development process and the impact on the environment," June 2018. ISSN: 2616-1125, The University of Port Harcourt, Journal of Private Law, special edition Volume 3 , pp. 76-107. Abila, Sylvanus, Ph.D: "The law and policy of environmental protection in Nigeria, existing challenges and impact on the global environment" (2018) Port Harcourt Law Journal, published by the Faculty of Law Rivers State University, Port Harcourt, Nigeria. ISSN: 1595 - 1790, Volume: 7: Number 1, February 2018.pp 92-108 etc.

${ }^{6}$ See Abila Sylvanus, Ph.D "A Review of the Challenges of Air Pollution in Contemporary Nigerian and Global Environment" (2018) being published by the Kwara State Collage Law Journal, Vol. 1 (current edition undergoing publication).

${ }^{7}$ See Chijioke, Basil Onuoha, Ebong, Itoro Bassey \& Henry Ufomba: The Impact of Oil Exploration and Environmental Degradation in the Niger Delta Region of Nigeria: A Study of Oil Producing Communities in Akwa Ibom State. Published by the Global Journal of HUMAN-SOCIAL SCIENCE, Volume 18 Issue 3 Version 1.0 Year 2018 P.13.

${ }^{8}$ Adeyinka, M.A., Bankole, P.O., and Olaye, S., Environmental Statistics: situation in Federal Republic of Nigeria. Country report presented at the Workshop on Environmental Statistics, Dakar, Senegal, from 28th February - 4th March 2005. 
as an environmental problem in Nigeria. This is perhaps, because there are no consistent emissions inventory for the country. Although there has been some independent research into air quality assessments in different part of Nigeria has stated earlier above, ${ }^{1}$ it is submitted that, it is incumbent on regulatory authorities in Nigeria to enforce existing laws and regulations directed at improving air quality in Nigeria. The Federal Environmental Protection Agency (FEPA) was originally established under the amended Decree No. 58 in 1992 as contained in the 2004 version of the Laws of the Federation of Nigeria to undertake the following functions, amongst others. ${ }^{2}$

i. Prepare a comprehensive national policy for the protection of the environment and conservation of natural resources, including procedures for environmental impact assessment for all development projects.

ii.

Prepare, in accordance with the National Policy on the Environment, periodic master plans for the development of environmental sciences and technology and advice the Federal Military Government on the financial requirements for the implementation of such plans.

iii. Promote co-operation in environmental science and conservation technology with similar bodies in other countries and with international bodies connected with the protection of the environment and the conservation of natural resources.

iv. Co-operate with Federal and State Ministries, Local Governments, statutory bodies and research agencies on matters and facilities relating to the protection of the environment and the conservation of natural resources.

It is unfortunate, however that, this law has since been abrogated by Section 36 of the National Environmental Standards and Regulation Enforcement Agency (Established) Act of 2007 which provides that "The Federal Environmental Protection Agency Act is [now] repealed." This author has, elsewhere criticized the abrogation as misguided. ${ }^{3}$ It is important, at this stage to examine the criminal sanctions under the criminal code and the harmful waste (special criminal for provisions etc.) Act respectively to see how these laws have strengthened the legal regime against atmospheric pollution.

\section{O.5 CRIMINAL SANCTIONS UNDER THE CRIMINAL CODE AND THE HARMFUL WASTES (SPECIAL CRIMINAL FOR PROVISIONS ETC) ACT NO. 42, 2004}

Under Section 234 of the Criminal Code, the offence of "Common Nuisance" is committed "where a person does anything, which obstructs or causes inconvenience or damage to the public in the exercise of rights common to all members of the public." This offence correlates with the common law offence of "Public Nuisance. It can be also raised to punish unlawful discharge of pollutions on public land as well as waters due to the inconveniences and damage to the public in the enjoyment of these rights, likely to be cause. Also under Section 245 of the Criminal Code, the offence is committed where there is "fouling" (corruption) of waters. For example, under Section 245 of the Criminal Code, it is on offence on the part of any person who corrupts or fouls any spring, stream, well tank, reservoir or place so as to render it less fit for the purpose for which it is ordinary use. The offense is a misdemeanor, carries punishable under Section 247 of the Criminal Code. It is doubtful whether this provisions in the Criminal Code still serve any important purpose in the Niger Delta region of Nigeria, for example. However, under Section 247 of the Criminal Code, any person who commit "noxious acts which affect public health may be punished. This provision is particularly important if applied to gas flaring going on abated in the Niger Delta region.

It is necessary at this point to note, apart from the above law, however that, there exists several other local legislation enacted ostensibly to protect the environment. However, in the context of air pollution control, the following matters may constitute a statutory nuisance if they are either prejudicial to health or a nuisance:

a. Any premises in such a state so as to be harmful to health or a nuisance; smoke, fumes or gas emitted from premises so as to be prejudicial to health or a irritation;

b. Any dust, steam, smell or other effluvia arising on industrial, trade or business premises.

Let us now consider the legal regime against air pollution under international environmental law.

\subsection{INTERNATIONAL PROTECTION AGAINST AIR POLLUTION:}

Global interest against atmospheric pollution is founded on the fact that, far from been a local problem, it has trans-boundary impacts. This can be illustrated from the fact that air pollution in the territory in one nation may also cause environmental damages and impacts in another country. ${ }^{4}$ References are often made, for example, to

\footnotetext{
${ }^{1}$ Baumbach, G., Vogt, U., Hein, K.R.G., Oluwole, A.F., Ogunsola, O.J., Olaniyi, H.B., and Akeredolu, F.A., Air pollution in a large tropical city with high traffic density - results of measurements in Lagos, Nigeria. The Science of the Total Environment, 169, pp. 25-31. 1995.

2 Federal Republic of Nigeria, Constitution of the Federal Republic of Nigeria 1999. Online: http://www.nigerialaw.org/Federal\%20Environmental\%20Protection\%20Agency\%20(Amendment)\%20Decree\%2 No.\%2059\%201992.htm

${ }^{3}$ See D.K. Derri \& Sylvanus Elijah Abila: A critical examination of the National Environmental Standards and Regulations Enforcement Agency (Establishment) Act, 2007 published in Law and Petroleum Industry in Nigeria current challenges (2009) ISBN: 978 978 023 2656 P. 1-10.

${ }^{4}$ See generally E. B Weiss, “Trans-boundary Air Pollution: International Legal Aspects of the Cooperation of State” 82 AJIL. 197,198 (1988) (noting pollution has no recognition of borders). Trans-frontier pollution includes loss of biological diversity. Id. at 198 .
} 
the fires which originated in Indonesia, several years ago which brought about haze smoke and particulate pollution which did not only affect Indonesia but caused severe negative impacts in Thailand, Philippines, Singapore, Brunei and Papua New Guinea. ${ }^{1}$ Worthy of note also, is the fact that an estimated $1 \frac{1}{2} \%$ of the entire acid deposited on Canada originates from the United States of America. On the other-hand, Canada is also credited with the generation of $20 \%$ acid deposition in the United States. The point to note in all this, however, is whether International Law can be applied as an instrument to regulate trans-boundary air pollution. In other words, the question one can ask, is whether, a particular country from which air pollution originates can be sued by another country for negative impacts caused by trans-boundary pollutions to a different nation?

Amokaye G. Oludayo has, in his book, Environmental Law and Practice in Nigeria, succinctly examined the current position of trans-boundary air pollution in the light of developments in the advanced nations vis-à-vis African Nations, admirably, as follows: "International response to long-range trans-boundary air pollution is elaborately expressed in customary law and treaties negotiated bilaterally or at regional levels to address the issue of air pollution. Incidentally, while efforts are being made by developed countries of West to address the issues of long-range trans-boundary air pollution at bilateral and regional levels in Europe and America, which cumulated in the negotiation of the Long Rang Trans-boundary Air Pollution Convention and the 1991 USCanada Bilateral Air Quality Agreement, there appears to be no significant effort by African States to address the problem. The absence of such Convention may not be unconnected with the fact that African countries are more preoccupied with social, economic and political problems. It is equally not unconnected with the fact that there is no credible scientific evidence to trigger continental action on the problem. Consequently, the discussion on international treaties on air pollution discussed here is not particularly relevant to Africa. But African States should draw inspiration from them when confronted with the need to negotiate air pollution convention either at regional or continental level." 2 This is an unfortunate lacuna in our anti-air pollution laws not only in Nigeria but also in Africa which must be given urgent attention.

CUSTOMARY LAW: In the well-known Trail Smelter's Case ${ }^{3}$ the tribunal in applying, the existing international law, in the area held, amongst other things that:

"Under the principles of international law..... no state has the right to use or permit the use of its territory in such a manner as to cause injury by fumes or into the territory of another or the properties or person therein, when the case is of serious consequence and the injury is established by clear and convincing evidence."

Hunter, Salzman and Zaelke, in their book: International Environmental Law and Policy ${ }^{4}$ argued that though, the Trail Smelter Arbitration did not technically constitute a legal precedent for similar disputes, in the light of the fact that it was a decision which was based on a relatively restrictive settlement on an agreement amongst the two parties; all the same, the thinking in Trail Smelter is still persuasive today, not only in cases involving trans-boundary air pollution but also applies to international environmental law generally. This is clear as it has found expression in Principle 21 of the Rio Declaration which have received global acceptability.

TREATIES: It is appropriate to discuss this part of the paper by stating that the drive to curtail the incidence of atmospheric pollution at global level started in the year 1979 upon the conclusion of the 1979 convention on Long-Range Trans-boundary Air Pollution. ${ }^{5}$ It is worthy of note however that, before then, the nations in Europe have continued to monitor the emission of $\mathrm{SO}_{2}$ and $\mathrm{NO}_{\mathrm{x}}$ pollution budgets for most countries and that the earlier before then, the said treaty was negotiated among the States in Europe. However, the United States of American and Canada also subsequently ratified same. Amodaye G. Oludayo further asserted that: "The Treaty was the first environmental treaty signed by both East and West apparently as a result of the end of the Cold War between Europe and USA. The objective of the convention is to protect man and his environment against air pollution and to striving to limit and, as far as possible, gradually reduce and prevent air pollution, including long-range trans-boundary air pollution". "Contracting States are required inter alia to initiate policies and strategies for exchange of information, consultation, research and monitoring as a means of combating the discharge of air pollutions. The Convention also sought for cooperation among members states in the areas of research and development of existing and proposed technologies for reducing emission of sulphur compounds and other major air pollutants, including technical and economic feasibility and their environmental consequences. It also seeks to study the effects of sulphur compounds and other major air pollutants on human health and the environment. These include research in the areas of agriculture, forestry, material aquatic and other natural ecosystems and visibility, with a view to establishing a scientific basis for dose and effect

\footnotetext{
${ }^{1}$ N. Dudley, The Year the Wold Caught Fire, WWF International Discussion Paper (Gland, Switzerland, WWF December 1997).

${ }^{2}$ See Amokaye G. Oludayo: Environmental Law and Practice in Nigeria published 2004 by the University of Lagos ISBN 978-077-625-X p. 390

${ }^{3}$ Trail Smelter Arbitration (United State v. Canada) 3 R.I.A.A. 1907 (1941)

${ }^{4}$ See Hunter, Zalman and Zaelke (eds), International Environmental Law and Policy, op. cit. p. 511

${ }^{5}$ Geneva, 13 November 1979 in force $16^{\text {th }}$ March 1983, 18 I.L.M. (1979) 1442.

${ }^{6}$ See footnote 23 above at P.391.
} 
relationship designed to protect the environment. It also has its objective capacity development through education and training programmes in related aspects to air pollution and long-rang trans-boundary effect. The treaty has been followed by a number of other protocols. ${ }^{1}$ The Protocol institutes a clear target and timetable, by freezing emissions at 1987 levels. Is also specifies certain technology-based standards, including, for example, a requirement to make unleaded gasoline available. Finally, the $\mathrm{NO}_{\mathrm{x}}$ protocol requires parties to begin gathering information for a critical load approach, which as of 1997 parties were still negotiating."2

\subsection{EMERGING RECENT DEVELOPMENTS}

In winding on this paper it is in important to refer to the recently - developed The Flare Gas (Prevention Of Waste And Pollution) Regulations, 2018 and the Nigerian Gas Flare Commercialization Programme (NGFCP) of the Federal Government of Nigeria which is ostensibly developed to "curb gas flaring --- with the issuance of the Flare Gas (Prevention of Waste and Pollution) Regulations, 2018 (the Regulations), which is the latest in a long line of legislation and policy measures aimed at reducing and ultimately eliminating gas flaring in Nigeria. Prior to the issuance of the Regulations, the 2017 National Gas Policy (NGP) had articulated the Federal Government of Nigeria's (FGN) commitment to achieve a flare out date in 2020, by adopting a combination of targeted policy interventions such as requiring oil companies to mandatorily include viable and executable gas utilization plans in their field development plans. The NGP had also buttressed the need for upstream companies to maximize utilization of their associated gas; and expressed the FGN's intention to work collaboratively with industry, development partners, providers of flare-capture technologies and third party investors towards ensuring that flare capture and gas utilization projects are developed and the (NGFCP) which was also developed to provide "a market-led mechanism aimed at attracting competent third party investors to commercialize Nigeria's flared gas." The Regulations sets out the legal and commercial framework for the commercialization of flared gas by the FGN through Permit Holders. ${ }^{3}$ It is only hoped that the above mentioned regulations will be implemented to the letter since the ultimate intention behind the said regulations is to phase out gas flare in Nigeria in the year 2020. ${ }^{4}$ Based on the above the following recommendations are made.

\section{CONCLUSION}

Air pollution in Nigeria's Niger Delta region and other parts of the globe is an issue that request urgent attention by the Nigerian authorities and multinational oil companies operating in the area because gas flaring and atmospheric pollution has being occurring for a long time without the needed application of existing laws, rules, treaties, international conventions and international customary law dealing with trans-boundary atmospheric pollution and its control and management. It is a cheering news that The Nigerian government, has repeatedly expressed, its desire, to phase out gas flaring in the Niger Delta in the near future. In view of this, the Nigerian National Space Research and Development Agency (NASRDA) is reportedly funding the research titled, "applying remote sensing and GIS techniques to air quality and carbon management, a case study of gas flaring in the Niger Delta." The research, which commenced in January 2008 at the University of the West of England, aims to integrate in-situ measurements of ambient concentrations and emissions with satellite remote sensing data to assess air quality emissions and $\mathrm{CO} 2$ concentrations resulting from gas flaring in the Niger Delta. The available satellite technology resources at NASRDA will combine with the European expertise in air quality studies available at UWE to proffer solutions to air pollution and air quality management in the Niger Delta. ${ }^{5}$

\section{RECOMMENDATIONS:}

1. The authorities in Nigeria must now fully explore the potentials for gas utilization in Nigeria. It is proposed that Nigeria make concerted efforts to ensure that henceforth flared gas is utilised to provide adequate power generation for the nation.

2. It is also recommended that government lay gas pipelines across the major industrial areas of Nigeria to supply gas for the purpose of running of industries. This will reduce manufacturing reliance on burning of liquid and solid fossil fuels for energy and ensure the use of cleaner gasolines to run manufacturing operations in Nigeria.

3. More than ever, there is now an urgent need to develop a vigorous intensive care and management system, which ensure that high quality information on the extent and impact of air pollution can be used as the basis for legislation to curtail the pollution and develop a mechanism that will enhance clean air when gas flaring ends in Nigeria.

\footnotetext{
${ }^{1}$ See Protocols of 1984 (Geneva), (1985) (Helsinki) 1988 (Sofia) 1991 (Geneva) and 1994 (Oslo).

${ }^{2}$ Ibid. see P. 392.

${ }^{3}$ See The Flare Gas (Prevention of Waste and Pollution) Regulations, (2018) printed and published by The Federal Government printer. Lagos. Nigeria FGP78/82018350, Government Notice No. 59. See also www.ngfcp.gov.ng $>$ media $>$ flare-gas-p... Accessed on the $12^{\text {th }}$ day of December, 2018

${ }^{5}$ Ibid.
} 